IOS Press

\title{
Erratum
}

\section{Biopharmaceuticals in the Russian Federation: A snapshot of policies for registration, reimbursement and use}

Lilia E. Ziganshina, Ravil R. Nyazov and Airat U. Ziganshin

[International Journal of Risk \& Safety in Medicine 21(1,2) (2009), 75-88]

In this article as originally published, the following should be corrected.

Two referrals to Table 3 in the discussion (the third line of the Discussion section, page 85), should in fact be referrals to Table 4 . 